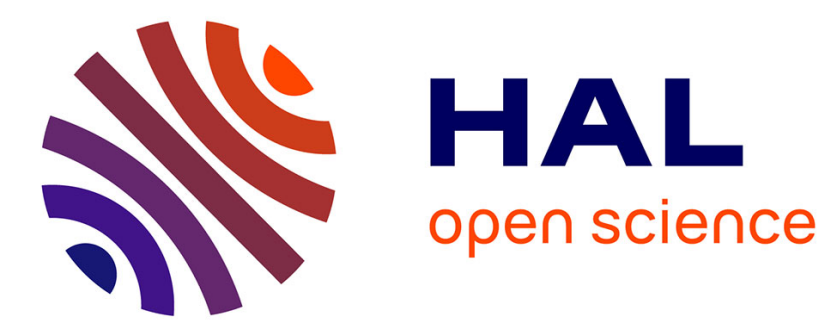

\title{
Long tails in the tourism industry: towards knowledge intensive service suppliers
}

Christian Longhi, Sylvie Rochhia

\section{To cite this version:}

Christian Longhi, Sylvie Rochhia. Long tails in the tourism industry: towards knowledge intensive service suppliers. 2015. halshs-01248302

\section{HAL Id: halshs-01248302 \\ https://shs.hal.science/halshs-01248302}

Preprint submitted on 24 Dec 2015

HAL is a multi-disciplinary open access archive for the deposit and dissemination of scientific research documents, whether they are published or not. The documents may come from teaching and research institutions in France or abroad, or from public or private research centers.
L'archive ouverte pluridisciplinaire HAL, est destinée au dépôt et à la diffusion de documents scientifiques de niveau recherche, publiés ou non, émanant des établissements d'enseignement et de recherche français ou étrangers, des laboratoires publics ou privés. 


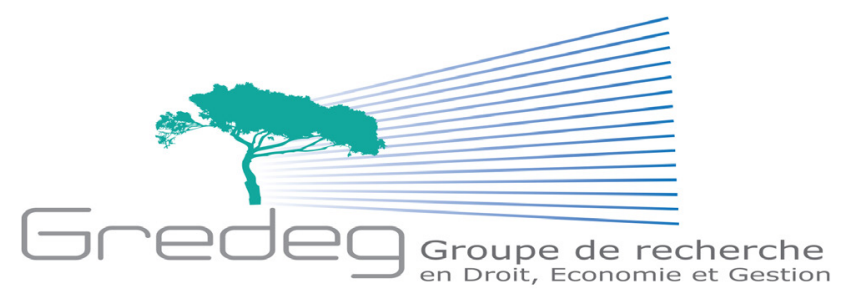

Université

nice

Sophia Antipolis

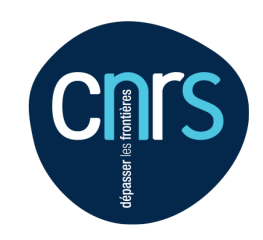

\title{
LONG TAILS IN THE TOURISM INDUSTRY: TOWARDS KNOWLEDGE INTENSIVE SERVICE SUPPLIERS
}

\author{
Documents de travail GREDEG \\ GREDEG Working Papers Series
}

\section{Christian Longhi Sylvie RochHia}

\section{GREDEG WP No. 2015-07}

http: / / www.gredeg.cnrs.fr/working-papers.html

Les opinions exprimées dans la série des Documents de travail GREDEG sont celles des auteurs et ne reflèlent pas nécessairement celles de l'institution. Les documents n'ont pas été soumis à un rapport formel et sont donc inclus dans cette série pour obtenir des commentaires et encourager la discussion. Les droits sur les documents appartiennent aux auteurs. 


\title{
Long Tails in the Tourism Industry: Towards Knowledge Intensive Service Suppliers
}

\section{Christian Longhi}

\section{Sylvie Rochhia}

University Nice Sophia Antipolis, GREDEG, CNRS, 250, Rue A. Einstein, Sophia-Antipolis, 06560 Valbonne, France

longhi@gredeg.cnrs.fr, rochhia@unice.fr

\author{
GREDEG Working Paper No. 2015-07
}

\begin{abstract}
This paper analyses the effects of the Internet on the organizations and the markets in the tourism industry. It enlightens its deepening impact on incumbent organizations and markets from Web 1.0 to Web 2.0 though the analysis of the dynamics of the long tail, i.e. of the distribution of activities in tourism. Innovation is gone from exploitation to exploration of the long tail, towards the emergence of non-profit or for-profit Knowledge Intensive Service Suppliers allowing 'prosumers' to find solutions to run themselves their activities, through users generated resources. Contrasting results appear, the growing autonomy of the tail from the head of distribution in the tourism industry, i.e. the development of global innovative market places inside the long tail itself, but still the reemergence of power laws, of tails within the tails as the basic shapes of activities in this platform economy. Skewed distributions appear indeed as the 'normal' characteristic of the economic activity, the traditional market one as well as the so-called 'sharing' one, which stands as a new form of the globalization.
\end{abstract}

Keywords: Tourism, Knowledge Intensive Service Suppliers, Sectoral Systems of Innovation and Production, Long Tail, Organization of the Industry, Internet

JEL: L83, L86, L31, O33, O35

\section{Introduction}

This paper aims to apprehend recent impacts of the Information and Communication Technologies (ICT) on the tourism industry. It shows that waves of more and more disruptive innovations have changed dramatically the composition, arrangement and organization of the industry, the last one implemented by entrants we define as Knowledge Intensive Service Suppliers challenging even its existence.

With roughly $10 \%$ of the world total employment or GDP, tourism is often presented as the first worldwide industry. It is also one of the fastest-growing economic sectors in the world; international tourist arrivals grew for instance (overnight visitors) by 5\% worldwide in 2013, reaching a record 1087 million arrivals. Europe is by far the first tourist international destination continent, but the USA have been and are the engines of innovation and changes in the industry. 
This economic strength of tourism, associated to a high growth potential, has continuously induced deep competitive processes and significant industrial reorganizations.

The entry of new actors, sometimes qualified of 'barbarians' in the literature (Wade, 2001), as they enter with self-defined new rules, is a constant characteristic of the modern period. The entrants have in fact exploited unused growth potentials and recombined the markets, or developed basic organizational innovations usually based on opportunities given by the new technologies of communication. Information and Communication Technologies (ICT) have indeed considerably impacted tourism (Buhalis, 1998; Wade \& Raffour, 2000, Buhalis \& Law, 2008). As it will be shown, the last entrants have deeply disrupted the main characteristics of the activity, from the nature of the competition to the organization of the markets and the industry. Innovation can be considered as a key word of this process (Aldebert et al., 2011).

The paper does not pretend to exhaustiveness regarding the multiple aspects and dimensions of the tourism activities and the upheavals implied by the development of ICT on the tourism industry. It apprehends the main changes and challenges to the industry through the evolution of the 'long tail' in tourism, i.e. the analysis of the evolution the distribution of the activities, destinations and accommodations and the engines of these dynamics. The notion of 'Long Tail' was invented by Anderson (2004) to characterize the impact of the Internet on the markets. It is used in this paper to organize facts and ideas, as its dynamics embody the main changes in the tourism industry. Indeed, the dynamics of the distribution of activities in the industry reflect the basic changes and challenges in tourism this paper aims to grasp.

As already coined, innovation is a candidate to explain changes. Nevertheless, tourism is complex, and innovation and changes cannot be addressed directly, as usual cases of technological changes. The tourism industry gathers all the activities dedicated to the satisfaction of the needs of the tourists, and borrows to a multitude of other activities. The tourist products are complex and heterogeneous products, combination of elements separated in time and space (Caccomo \& Solonandrasana, 2001). The first part of the paper is thus devoted to a definition of the industry and the relevance of the 'long tail' in tourism. The second part deals with the nature of changes in the long tail. It shows that it is possible to trace and rationalize two main phases in its evolution, corresponding to the switch from Web 1.0 to Web 2.0. These two phases can be characterized as exploitation and exploration of the long tail, the last one being related to the surge of platforms, we define as Knowledge Intensive Service Suppliers, and to deeper and deeper innovative changes, from Users Generated Contents to Users Generated Resources. 


\section{The 'Long Tail' in the tourism industry: definitions and issues at stake}

\subsection{Tourism as a Sectoral System of Innovation and Production}

The ICT have been shown to underlie the contemporaneous logics of reorganization of activities and markets, the emergence of new markets, or of the strategies of the actors. Tourism has played a pivotal role in this process "technological progress and tourism have been going hand in hand for years" (Buhalis \& Law, 2008: 610), reducing the uncertainty related to the products via forums, or improving information of prices for instance. Far beyond the eases or improvements of the working of the existing operations or activities, the Internet has basically induced an in depth renewal of the industry (Buhalis \& Zoge, 2007), not linked to the working of existing markets, but to the revolution of the organization of the industry.

Tourism is not a simple 'sector' in the usual sense (Leiper, 1979) but an industry which encompasses all the activities dedicated to the satisfaction of tourists' needs and borrows from multiple activities (Longhi, 2003). The industry relies on the organizational complementarities and interdependences among actors and groups of actors, sharing responsibility for and planning tourist flows and needs (Tremblay, 1998), on firms that purposely undertake joint coordination of their activities for serving the tourists (Leiper, 1979). The concept of system emerged as the most suitable analytical framework to cope with tourism (Leiper, 1979; Buhalis \& Licata, 2002; Baggio, 2008, Longhi, 2009).

The tourism industry gathers the firms that purposely undertake the joint coordination of their activities for the purpose of serving the tourists (Tremblay, 1998). The coordination of the activities becomes the core issue which points out the importance of an analysis of actors and their interactions. The tourism industry will thus be defined as a Sectoral System of Innovation and Production (SSIP) as defined by Malerba (2001: 3), i.e. " $a$ set of new and established products for specific uses and the set of agents carrying out market and non-market interactions for the creation, production and sale of those products. The agents are individuals and organizations at various levels of aggregation with specific learning processes, competences, organizational structure, beliefs, objectives and behaviors. They interact through processes of communication, exchange, cooperation, competition and command, and their interactions are shaped by institutions (rules and regulations). Over time, a sectoral system undergoes processes of change and transformation through the coevolution of its various elements".

According to Malerba (2002, 2004) and Tether \& Metcalfe (2004), a SSIP is characterized by a set of attributes or building blocks that evolve over time, and specify the components and 
modes of interaction of the system. These attributes are the knowledge bases and technologies, the organizations (firms, non-firms, networks), the institutions, and the existing, emergent and potential demand; they help to explain the constraints linked to the specificity of the tourism innovation process (Hall \& Williams, 2008). The sectoral system is an open system, with evolving boundaries triggered by evolving attributes along innovation processes.

The SSIP allows to organize the analysis of the interactions and feedback effects between the different actors involved in the industry, and to apprehend the evolution of the activity. Changes in one of the element of the system can lead to important reconfiguration of interactions or coordination processes (Hjalager, 2002, 2010, Werthner \& Klein, 2005). The multiplicity of the recent interdependent evolutions - new technologies, new products, new markets, new rules

- has triggered changes that inclines to privilege such an approach of the industry as the relevant space of the coordination of the activities. The emergence of new knowledge bases is usually followed by the emergence of new actors or markets, by the transformation of existing markets. The basic role played by the internet in tourism represents an important source of changes. The boundaries of the systems are not predefined, but change over time with the evolution of the knowledge bases (Murmann, 2003).

\subsection{The Long Tail: issues at stake}

Since the development of the Internet, all the attributes of the tourism industry have deeply and continuously evolved, new entrants, new knowledge bases, new arrangements of markets and organizations reshape the industry. This process has even been sped up recently by the emergence of disruptive innovations, from the evolutions of the web to the emergence of a platform economy to the mobile technologies. The long tail is used in the paper as a device to grasp and synthesize this complexity.

Mass tourism has been the main feature of the tremendous growth of the tourism industry. This mass effect refers to the destinations, some places capture disproportionate shares of tourists, traditionally London (top rank in 2014 with 18.7 million of international visitors), Paris or New York, and recently Bangkok, Dubai or Singapore as a result of the ongoing globalization, are the most visited cities in the world (Hedrick-Wong \& Choong, 2014). The mass effect refers too to the accommodations, concentration of tourists in huge hotels, parks or complexes run by multinationals. The mass effect refers indeed too to the operators, large multinationals which drive deep concentration processes, vertically as well as horizontally. Some German or American 
tour operator firms were dominating the market, but internet oriented strategies or actors have been more important in the USA.

This economy of 'superstars' (Rosen, 1981) is characteristics of the tourism activity; as coined by Miranda (2012), 'maxmin' could be the summary of the economic model, a maximum of tourists in a minimum of destinations, of accommodations, to the benefit of a minimum of actors. The distribution resulting from this model is well known, it refers to the power law distribution, also coined as Pareto distribution or again Zipf law, where $80 \%$ or more of a phenomenon is to the benefit of $20 \%$ or less of actors, and is universally present, for the size of cities, for incomes, and then for tourism. From a distribution point of view, the world is very scarcely 'normal'.

As emphasized by Anderson (2008:139) "one of the features of power laws is that they are "fractal," which is to say that no matter how far you zoom in the distribution of the phenomenon following the law still look like power laws. Mathematicians describe this as "self-similarity at multiple scales," but what it means is that the distribution is made of many mini-tails, each of which is its own little world. When you look closely at the data, you can see that the big powerlaw curve of, say, "music" is really just the superposition of all the little power law curves formed by each musical genre". And so it goes in tourism, for the destinations as well as for accommodations (Day et al., 2011). The Internet has impacted significantly the distribution of activities, resulting in the lengthening and thickening of the tail of the distribution, as well as a relative decrease of the share of the head. And as underlined by Day et al. (2011), the power law curve of a tourism demand can be seen as the superposition of all the power law curves formed by each destination/accommodation, of tails within each tail, which implies more opportunities for niches.

So, the development of ICT has resulted in the growth of niche-destinations, "opening up those previously uneconomic niche markets should increase overall demand: as people are better able to explore niches, they are more likely to find things they like, and may well consume more of them”, profiting from obscurity (The Economist, 2005). This process has been characterized by Anderson (2004) as “Long Tails" in the distribution of tourism demand (Anderson, 2004, 2008; Brynjolfsson et al, 2010, 2011). The economics of this new tourism is very different from the old. Profitability no longer rests solely on economies of scale and the exploitation of mass undifferentiated markets (Lew, 2008). "Economies of scope, systems gains, segmented markets, designed and customized holidays are becoming more and more important for profitability and 
competitiveness in tourism” (Poon, 1989:93, quoted in Lew, 2008).

Figure 1. 'Internet has changed the dynamics of the market place'

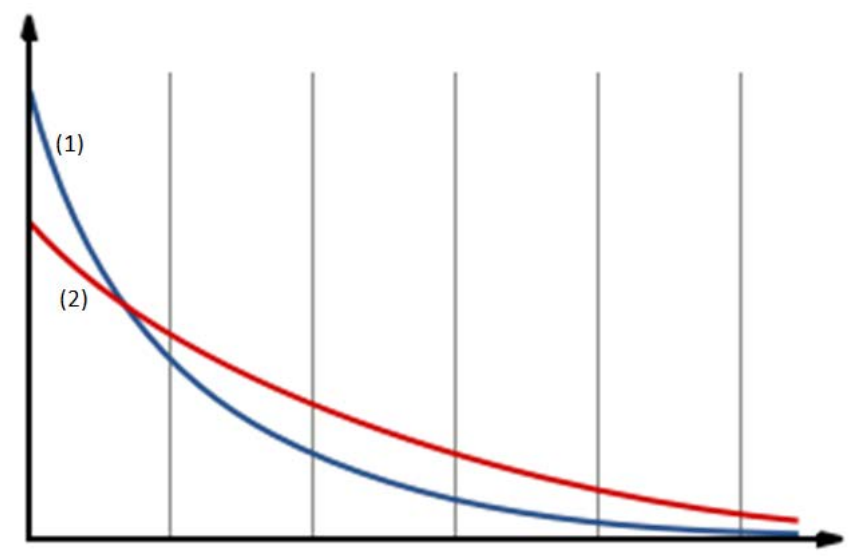

The Figure 1 depicts the evolution of the distribution according the 'long tail', from the blue (1) to the red line (2), a lesser share for the head and a larger share for the tail, which is lengthening and thickening. It is often referred that "long tail economics is a new perspective on economics of small, independent and individual businesses and activities, as opposed to large scale, multinational mega-corporations. The issue is how a multitude of small, independent operators can compete with large mega-operators, or whether they should even try” (Lew, 2005). This can indeed reflect the evolution, but complex dynamics are at work in the tourism industry. Different effects can result from the exploitation of the long tail in accommodation for instance, to the benefit of the small or on the contrary of the large operators. The long tail of accommodation is not a priori to the benefit of increased competition; it could work to the benefit of concentration of the firms, as it will be shown. Tourism is a sectoral system, the evolution of its attributes can follow either opposite or matching trends, for accommodations and operators for instance, depending of the causes and consequences of the changes. From this perspective, there are different stages impacting differently the sectoral system, from Web 1.0 to Web 2.0, from innovation to disruption. At the level of the long tail, following March (1991), we discriminate between 'exploitation of old certainties' and 'exploration of new possibilities'. This discrimination seems indeed to fit many other evolutionary notions as for instance the distinction between routinized and learning behavior on one side and innovative behavior on the other side. 


\section{The 'dynamics of the long tail: from innovation to disruption}

\subsection{Long Tail 1.0 : Exploitation}

The Internet has induced deep changes in the knowledge bases and demand in the tourism industry, as well as the entry of new actors and the definition of new rules. Tourism as such is obviously not the locus of radical technological innovation. Nevertheless, innovative technologies and knowledge bases have always been used to benefit from market opportunities and to reorganize the industry. Tourism has always been at the technological frontier regarding ICT, and e-tourism has been synonym of e-commerce during years. The reorganization of the markets and the industry has resulted in emerging dynamics in the 'long tail', towards lengthening and systematic exploitation of the competitive advantages it can confer.

A first impulse has been the creation of low cost carriers in the transport; the low cost are not a technological innovation, but have used all the dimensions of the Web 1.0 to implement a revolution in the transport activity. Point to point, internet reservations have among other organizational changes allowed lower prices and increasing market shares. The entry of low costs had huge consequence of competition and markets shares of airlines carriers, and a related consequence on the long tail of destinations. The leading ones, Paris, London, gained from the fact that they benefited from efficient airports, monopolizing most of national and international arrivals. The low costs have re-opened existing but disused airports in the periphery of the 'superstar' destinations and also on disused destinations or regions from a tourism point of view. In France for instance, regions like Dordogne, Limousin have benefited from this rearrangement of the industry, and based local development on tourism through the growth of international arrivals. The result is the creation of new and often more affordable destinations and accommodations which impact the tails.

A second impulse has been the development of online electronic agencies and the deregulation of the distribution markets; airlines and hotels compete now with agencies to sell their products on internet (Longhi, 2009). The electronic agencies, Travelocity, Expedia, Orbitz, have taken important shares of the market, and built huge multinationals aggregating numerous specialized sites to benefit from the increasing demand of niches products (Classic Vacations, eLong, Hotels.com, and Hotwire.com). Thevenot (2007) suggested that the short head consists of the large hotel aggregator websites (expedia.com, hotel.com), followed by larger niche market sites (lastminute.com, corporate travels), hotels own sites, apparently in contradiction with the long tail. 
The changes resulting from the e-commerce have been analyzed in-depth through the case of Amazon in the book industry, coined by Brynjolfsson et al. (2011) "Good bye Pareto principle, Hello Long Tail”. The issue is online sales versus offline sales; brick and mortars shops have physical constraints which mainly limit their supply to the "superstars" that concentrate most of the demand. Online sales do not face such constraints, the supply can be without limit. For Anderson (2004) the aggregation of the sales of books with low demand coming from the long tail can result profitable and balance the previous short head. Brynjolfsson et al (2011) have shown that the long tail has grown overtime, in 2008 niche books accounted for $36.7 \%$ of Amazon sales. This process has been somewhat equivalent for the online sales in tourism, the niche destinations and accommodations have deeply increased, but has not worked against concentration, on the contrary. Amazon for instance sells books belonging the whole distribution, short head best sellers and low sales books, when most of its competitors are restricted to the short head books. It has been possible for Amazon to support very low prices on these best sellers, because additional revenue was allowed from the long tail. The impossibility for its competitors to support such aggressive pricing strategies has resulted in many failures and concentration of the market in global firms. The same strategy has resulted in the bankrupt of main travel agencies and in the concentration of the activity in global groups, vertically and horizontally integrated from agencies to $\mathrm{GDS}^{1}$ to search engines to specialized agencies to benefit totally from the long tail. The long tail in product does not go necessarily with increasing competition; the existence of the long tail is the solution for some firms to destroy existing rivals. There is an increasing number of occurrences far from the head of the distribution, of niches, a longer and larger tail, but the 'winner takes all' logic of the mass markets remains.

A third and last impulse - among many others - we will discuss in this paper is the huge changes in the demand side, not only quantitatively but also qualitatively. Mass tourism is more and more challenged by the consumers who prefer specialized niches for destinations as well as for accommodations. The diversification of products is steadily growing overtime. But mainly the consumers have taken more and more importance in the working of the industry. The market share of ready packages offered to the consumers has deeply decreased overtime; from now many years the consumers build themselves their packages, assembling different products after active search on Internet. The tourism goods are also experience goods, whose utility, quality are uncertain and only known ex post. A system of advices and signaling has to be built to allow

\footnotetext{
${ }^{1}$ Global Distribution Systems
} 
choices; the old system of critics has been challenged by the advices posted by the consumers themselves on the web, webpages, communities of experience have emerged with the Web1.0. So tourists have contributed more and more to the production of information and used extensively social networks in such a way that collaborative mapping and contribution platforms also raise the question of the value of this information. This system characterized by information asymmetry has resulted in organized exchanges without commercial aims, usually personal pages which have finally aggregated communities. The importance of the phenomenon (Kozinets, 1999; Kim et al, 2004, Wang et al., 2002) attests the emergence of a rationality which prioritizes cooperation and reciprocity through the usages of internet.

After the production of information allowing the formation of choices, the consumers have thus entered directly in the production of the tourist products themselves. They stand as a fullfledged actor of the industry: they can buy online air or train tickets directly to suppliers, but also build themselves their packages adding online the purchases of accommodation, on site transport, leisure. The consumers exchange and capitalize their experiences, they have a direct access to the quasi-totality of the services supplied, to the prices posted by the different suppliers, they can fulfill the transactions online. They can thus execute the tasks of research and bundling previously exclusively assigned to agencies and tour operators, through direct relations with services providers and suppliers. Consumers have changed into consum'actors, pivotal elements of the sectoral system of innovation and production, and will even evolve to prosumers, actors on both sides of the markets. The emergence of mobile technologies, a disruptive innovation, has deepened the pivotal role of the consumers in the working of the industry. The organized professional top down critic system was in line with mass tourism, the selection of the products signaled being driven by the industry itself. The entry of the consumers has run towards an increasing number of information and advices on niche products, innovative leisure, new modes of consumption..., with a direct impact on the long tail, whose length and thickness increase in destinations as well as in accommodations. Tails within tails within tails are growing through the working of the demand side, which drives more and more the evolution of the industry and the challenges the firms have to face. Many others changes have obviously occurred during this Web1.0, we will not address in the paper; the mobile and the convergence of technologies have also deepened and increased the effects of the related changes on the industry. Indeed, "the smartphone revolution has moved the Web from our desks to our pockets. Collective intelligence applications are no longer being driven solely by humans typing on keyboards but, increasingly, by sensors. Our phones and cameras are being turned into eyes and ears for applications; motion 
and location sensors tell where we are, what we're looking at, and how fast we're moving. Data is being collected, presented, and acted upon in real time. The scale of participation has increased by orders of magnitude” (O’Reilly \& Battelle, 2009). But even more disruptive development related to the long tail will come out with the arrival of Web 2.0, the social one, which exacerbates the network and cumulative effects.

\subsection{Long Tail 2.0: Exploration}

\section{3.}

3.3.1. The dynamics of the long tail in tourism have changed dimension with the takeoff of the social web, the Web 2.0, and the deepening of the knowledge based economy (Liburd, 2012). The Long Tail is becoming autonomous and competes directly with the Short Head, unintended consequence of the emergence of a platform economy and its aggregation capacities.

The main features of the Web 2.0 explain its potential disruptive effects on the incumbent markets and industries, and even on the whole society. Its characteristics and main principles have been precisely defined by O’Reilly (2006). “Web 2.0 is the business revolution in the computer industry caused by the move to the internet as platform, and an attempt to understand the rules for success on that new platform. Chief among those rules is this: Build applications that harness network effects to get better the more people use them”. Different lessons and principle have afterwards been coined by O’Reilly (2006), for instance:

-leverage customer-self service and algorithmic data management to reach out to the entire web, to the edges and not just the center, to the long tail and not just the head;

-network effects from user contributions are the key to market dominance in the Web 2.0 era;

-the service automatically gets better the more people use it;

-when commodity components are abundant, you can create value simply by assembling them in novel or effective ways.

Web 2.0 refers mainly to social networks, to the emergence of platforms involving members of distinct groups to share experiences, advices through different media. The platforms are usually free for at least one side of the market, and tools to enable interactions or interventions are provided to uses. "They serve as matchmakers to facilitate exchange by making it easier for members of each group to find each other" (Evans, 2011a: 138). Platforms have flourished with Web 2.0, and it will be impossible to consider their diversity in this paper; Facebook has for instance deeply modified human relations, but platforms and social networks 
have also led to in-depth transformations of the industry, often as a consequence of the involvement of consumers into the production process, converting in some sense consumers into producers. In the tourism industry, it is the case for instance of TripAdvisor which has built on the first communities of experience created by the tourists themselves on the Web 1.0 age.

TripAdvisor allows the users to post advices, signaling, comments, notes on hotels, restaurants, destinations... Because of the important network effects and the 'winner takes all' effect working in the internet economy, TripAdvisor has rapidly taken the lead and has grown as a global firm, covering most of the tourism activities through User Generated Contents. The development of an application TripAdvisor for Facebook allowing 'friends' to share experiences and comments, as well as the development of the mobile technologies and smartphones, comments, advices, photos being posted in real time on the platform have strengthened these network effects.

TripAdvisor has important effects on the long tail, building on obscurity and forcing a bottom up standard which has overcome the top down system of professional advices and advertising. The visibility is no more seized by the short head, because of the Web 2.0 and the platforms all the elements of the distribution are equally visible, and new references are continuously added by users, independent producers as well as tourists. It has grown has a huge global group and operates 25 travel brands; it claims to be the "largest travel site in the world", with over 170 million reviews and opinions of hotels, restaurants, attractions and other travelrelated businesses and roughly 300 millions of visitors per month ${ }^{2}$. Without appearing to do so, TripAdvisor competes with different traditional actors of the industry. It is the leading reference for travel guides, the personal reviews and its peer rating system based on lots of users have ousted the established guides, on a worldwide scale. TripAdvisor rating is pivotal for professionals, and eWord of Month can have huge consequences on the activity. Some of them can raise questions about how to solve problems of information asymmetry and how to distinguish between facts, opinions and above all fake reviews. And the recent convictions of TripAdvisor, Expedia, Hotels.com for fake reviews underline the key role that institutions have to play in controlling these decentralized and interactive systems.

TripAdvisor is also continuously enriching the services it supplies, and allows users to solve a multitude of problems from its platform. Its search engine proposes ordered solutions for accommodation in a chosen destination for instance, but besides the direct links to reservation

\footnotetext{
${ }^{2}$ http://www.tripadvisor.com/PressCenter-c6-About_Us.html
} 
sites. Finally, the database TripAdvisor has built is certainly a major asset of the company. The business model of the platform has deeply evolved, advertising accounts now only for $13 \%$ of its revenues, the sale of data to professionals for $14 \%$, and commissions from booking sites for 74 $\%$, the sites being ordered by TripAdvisor according the level of the commission they consent. Facebook and TripAdvisor can be associated to the first generation of platforms of the Web 2.0, they offer free services for the users, which in turn feed the platform and confer its real value on the site. Consumers generate the contents which produce in some sense the economic value of the sites they use. The second generation will involve even more deeply the users in the economic model of the sites, towards platforms we will define as Knowledge Intensive Service Suppliers.

3.3.2. The ongoing revolution in the tourism industry is mainly driven by the co-evolution of two attributes of the sectoral system of innovation and production: technology and knowledge bases on the one hand, and demand on the other hand. This co-evolution matches the principles of the Web 2.0 set by O’Reilly (2006) and results in the exploration of the long tail. As in any economic revolution period, a lot of initiatives, of new rules are emerging and competing with the incumbent ones. The new economic arrangement will result from the evolution of another key attribute of the system, the institutions, which will select the new rules.

The Long Tail 2.0 is the consequence of a radical innovation, not a technological one, rather in the organization of the markets and the industry through the development of platforms. Web 2.0 allows building applications that involve a maximum of network effects and impact directly or indirectly heavily on competition. The platform economy is indeed redesigning most of the industry, not only tourism, shifting from products to (eco) systems. Nokia for instance was before 2000 the leader of the mobile phone technologies, and certainly the main innovator. It had remained the most innovative and technologically advanced firm, but it has gone on to sell selfcontained, closed products, when Apple decided to launch its App Store, a platform hosting millions of applications, and millions of connected users. Nokia has lost its position of leader not because of usual competition, technological innovation, but because it missed the platform switch. This clash between products and platforms is the pivotal explanation of the present evolution of the industries, and basically of tourism. The entrants do not compete directly on products, creating features that differentiate them from others, but they compete indirectly with incumbent firms providing the consumers tools to solve themselves their consumption problems through (often free) access to dedicated platforms (Evans, 2011b; Choudary, 2014). 
The successful platforms are the ones that have built the more network effects; these effects divert the consumers from the traditional markets on the one hand, and select the winners from the flourishing platform start-ups on the other hand, according to the 'winner-takes-all' processes working under the internet economy. As a mean to increase the interactions between people, citizens or consumers, technology is seen as a vector to create new business models and to disrupt existing markets. This surge of technology start-ups finds its foundation in the knowledge based economy grown with the internet, the so called "innovation in assembly" principle of Web 2.0. The issue to develop activities is no more only availability of financial capital but of knowledge, as far as many of the elements to build a platform are freely available on the web, the issue is the capability to assemble these elements, the needed hardware being more and more easily available and affordable. The result of the platforms is the disintermediation of incumbent models and emergence of the new, new markets, new modes of coordination of the activities, new organization of the activity.

Along with technology, demand is the other attribute which has disrupted the old economy. Consumer preferences, and particularly tourist preferences, have considerably evolved, the standardized products of the mass-tourism period do not match anymore the needs of the tourists, which are more and more independent travelers. This independence has followed different steps, independence from mass tourism products, destinations or accommodations, independence also from the traditional professionals, to build the platform economy. The mobile technologies, geolocalization and applications dedicated to smartphones have worked as an amplifier of this process. And this process can be read on the evolution of the long tail.

The diversification of the choices of the tourists can be measured by the proliferation of niches, whose market growth $20 \%$ annual rate, to $\$ 90$ billion. The evolving tastes of tourists have resulted in the creation of specialized segments, a profusion of niches. Just to refer to a part of the Wikipedia page on tourism, we can trace agritourism, birth tourism, culinary tourism, cultural tourism, dark tourism, doom tourism, ecotourism, experiential tourism, extreme tourism, geotourism, ghetto tourism, heritage tourism, LGBT tourism, medical tourism, nautical tourism, pop-culture tourism, religious tourism, sex tourism, slum tourism, slow tourism, sports tourism, virtual tourism, war tourism, wellness tourism, wildlife tourism ${ }^{3}$. Niches are often considered as the future of tourism, as given the possibilities of aggregation offered by the Web 2.0, the opportunity to build global businesses around these activities becomes viable. The segmentation

\footnotetext{
${ }^{3}$ http://en.wikipedia.org/wiki/Tourism
} 
of the market, the creation of specialized independent agencies and often the diversification of the leaders of the markets which run numerous affiliated sites have been induced to match this demand.

This trend can be considered as a revolution 'within the tail', as the capacity of aggregation of dispersed specialized small niches can be aggregated globally to reach a critical mass and benefit from the properties of the Internet, on which all the information is visible. The Internet does not make any hierarchy; the large operators are no longer the only suppliers globally visible on the markets. The net neutrality is a necessary condition of the viability of businesses based on the exploration of the long tail, as far as for instance, "google will find the little guy as easily as it finds the big guy” (Anderson interview, 2014). The emergence of small niches aggregators is the birth of new long tail travel marketplaces in tourism, and of increased lengthening and thickening of the tail.

Nevertheless, the massive exploration of the long tail has occurred recently with deep changes in the behavior of consumers or citizens, from individualistic towards more collaborative behaviors. The values shared in the Internet communities are certainly under the reemergence of 'commons' (Ostrom \& Hess, 2007), but the crisis, the ecological awareness have outgrown these movements towards the emergence of a sharing economy, a collaborative consumption (Botsman \& Roo, 2011). Uses prevail henceforth on ownership, goods are accessed only when needed, for what it is sometimes referred as "disownership" (Wang, 2013). The economic changes have been massive, and have disrupted lot of industries, because as it will be shown of the Web 2.0 and the development of platforms, of peer to peer marketplaces, on which far from the original idea of commons large global firms have grown. Sharing has moved from a community practice into the distinctive business model of the $21^{\text {st }}$ century.

Barter, sharing of goods are obviously as old as the hills, but the aggregation power of the Web 2.0 (according O’Reilly principles) has stirred up this model, peer to peer has moved from a common practice among friends towards a global model, a specific need of a citizen in the far end of Germany for instance can be satisfied by someone in the far end of Brazil, because they can eventually virtually meet on a platform, visibility and proximity are from this point of view perfects and can give rise to lot of new activities. For Stephens (Streetbank) "new business models will play a significant role in turning "the vicious circle of isolation, fear and mistrust" into a "virtuous circle of connectedness, belonging and trust".

The platform enables members of distinct groups to share, transact with each other, and to 
realize gains from trade by reducing the transactions costs of finding each other and inter-acting; so it is a "market-maker" (Evans, 2011a). Interaction between people is the key issue; the platform connects producers and consumers with each other. Producers can turn into consumers and vice versa, depending of their present needs. Everyone is a producer, everyone is a consumer, cutting out the traditional models of the market economy. In the traditional economy, producers and consumers had very specific, different and sequential roles; this linear model is overthrown in the platform economy, which gathers the different models born from the Internet. The first platforms allowed people to react and post comments on businesses, TripAdvisor for instance, the new ones allow people to run the businesses themselves and solve their problems, and are particularly present in the tourism industry.

We consider these platforms as Knowledge Intensive Service Suppliers (KISS), designed to help users to solve a specific problem in a unique way and create new value, either market or non-market value. Like the former Knowledge Intensive Business Services (KIBS), they involve an intensive use of high technologies, specialized skills and professional knowledge (Miozzo \& Grimshaw, 2006). The suppliers organize complex interactions between producers and users of tourist products, in particular accommodations, to facilitate transfer of information. But, unlike KIBS, these services are embedded in platforms and can be delivered by non-profit or for-profit organizations.

In the platform economy use, access to the goods or services prevail on ownership. Thus, the KISS can have deep influence on the organization of the industry, particularly in tourism, through the creation of communities or new arrangement of markets aimed at solving a particular need. The emergence of KISS is related to the aggregation of microscopic and fragmented actors in huge communities or markets, each microscopic actor being equally reachable, and equally visible than any other huge actor, according to the net neutrality principle. The more people involved and using the platform, the more efficient the platform and the service provided, as described in the definition of the Web 2.0. The platform appears as the organization matching perfectly the principles of the internet, allowing network effects to be somewhat optimized. The questions recently raised against the net neutrality are perhaps linked to the disruptive efficiency of these platforms, as they can induce huge upheavals of the established society.

The KISS are explicitly built on the exploration of the long tail. The communities, the arrangement of markets to organize exchanges, sharing, are internal to the long tail, and run by their own rules, free from the Short Head on which they finally compete, as the users of the KISS 
where the consumers of the large operators running head. This Long Tail 2.0 phase opens a deep rearrangement of the market economy.

3.3.3. A lot of platforms aggregating microscopic actors have flourished in many different activities related to the tourism industry, which have grown global KISS. These KISS can be of two kinds, non-profit and for-profit, collaborative consumption and sharing platforms, or peer to peer marketplaces. The cases we will shortly present in the paper stand as paradigmatic cases of the platform economy and are focused on the analysis of the accommodation in the long tail 2.0.

\section{i) Non-profit KISS}

The sharing economy has partly grown because of the crisis and the increasing income constraints lying on people, and because of the development of a culture of sharing. It is often said that the crisis has implied the necessity to gather, and this necessity in turn created the pleasure to gather. Internet is deeply involved in this process, because of the 'philosophy' promoted by its inventors, Creative Common licenses or open source software feeding the knowledge based economy. The Web 2.0 is defined by Battelle and O’Reilly (2006) as the 'web as platform', KISS applications built on this web allowing users to solve their problems and even build and run their own 'activities'. In the tourism industry, CouchSurfing has been one the success stories of the platform economy, as it pioneered the non-profit KISS in 2004 and moved to for-profit in 2011.

CouchSurfing has been created in 2004 by Casey Fenton and different associates as an association, a non-profit organization, which provides a platform for members to "surf" on couches by staying as a guest at a host's home, or to join an event. Registration is free of charge, as well as the stays. The platform provides the users, host or guest, the tools to organize the stays. Furthermore, different information are provided by the members of the platform, photos of themselves and of the 'couch' they offer, location, age, gender.

The idea of CouchSurfing formed in 1999, when traveling in Iceland, Fenton sent an email to a group of students asking for a free stay, to meet people and share experience. The important number of invitations gave "birth to the idea that people anywhere would want to share their 
homes with strangers (or, as we like to call them, friends you haven't met yet)" ${ }^{4}$. CouchSurfing is not a mere non-profit association; it is born as a common, the platform being developed by the members of the community. It has rapidly reached a critical mass allowing the matching between guests searching for a particular place and corresponding hosts worldwide. Trust between unknown users has been gained by systems of reputation, but above all by the belonging to a community and the adoption of rules following the general principle enacted by Hess and Ostrom (2007) to explain their sustainability. For instance, “define clear group boundaries”, "ensure that those affected by the rules can participate in modifying the rules”, “develop a system, carried out by community members, for monitoring members' behavior”, “use graduated sanctions for rule violators", "build responsibility for governing the common resource in nested tiers from the lowest level up to the entire interconnected system”. Clearly the "couches” are not only considered as products, but above all in relation to the community which provides and shares them, to the system of rules enacted for collective consumption. Resources as well as collective rules and governance are underlying Couchsurfing. The success has been immediate and very important, raising classical problems of growth. CouchSurfing was financed by the donation of its members, and developed by its members. It is clearly a by-product of the knowledge based economy and the Internet, innovation from assembly implemented because of the knowledge and not the capital of the members of the community and network effects. In 2008 the receipts of CouchSurfing were around \$ 800000 and a strategy had to be though to support its global growth and the resulting additional costs.

In 2011 the founder of Couchsurfing decided to dissolve the non-profit association to create a for-profit corporation, which bought the existing assets. As of august 2012, the company has raised \$22.6 million in investment capital. This decision has been vigorously put into question by some former members, who created a group, "We are against CS becoming a for-profit corporation”. The disinterested investment the members had made in the platform has been transformed into a for-profit firm. Clearly the previous quality of Common of CouchSurfing has disappeared, even if registration is still free of charge and the sharing is going without money exchange, only payment of a $\$ 25$ fee is asked to access to services, as part of the control and safety system. Still CouchSurfing is describing itself as "a global community of 9 million people in more than 120,000 cities [which] connects travelers with a global network of people willing to

\footnotetext{
${ }^{4}$ The CouchSurfing story, http://about.couchsurfing.com/
} 
share in profound and meaningful ways, making travel a truly social experience” ${ }^{\text {. }}$

The platform has recently made an important change, adopting a new Member Content License, which grant CouchSurfing “a perpetual, worldwide, irrevocable, non-exclusive, royaltyfree and fully sub licensable license to use, reproduce, display, perform, adapt, modify, create derivative works from, distribute, have distributed and promote such Member Content in any form, in all media now known or hereinafter created and for any purpose, including without limitation the right to use your name, likeness, voice or identity”. These new rules are in line with the business model enacted by Facebook or Twitter, the main asset of the firms being the data they generate. Finally the users of CouchSurfing are no more sharing couches with others users, they produce personal data for uncontrolled used, somewhat the opposite of a Common.

\section{ii) For-profit KISS}

The other paradigmatic example is certainly Airbnb, a peer to peer market place. As a consequence of the success of Airbnb, the continuous upsurge of peer to peer marketplaces had resulted in a huge lengthening and thickening of the long tail in tourism, homes, apartments, rooms, couches, boats, cars, camping... being available and allowing customers to solve any issue going with their stays. The huge growth of the long tail and of the related marketplaces in tourism has rapidly threatened the traditional industry. The competition has been indirect; traditionally for instance the hotels try to differentiate form other improving quality, advertisement, standards, to attract customers. The platforms have not competed in this sense, directly, they have simply offered customers services allowing them to solve their problems of accommodation, transport or other needs by themselves.

AirBnB has been created directly as a for-profit platform, exploiting unused growth potential or market failures related to accommodation in large cities, i.e. shortage of hotel in the centers, particularly during events where they host lot of tourists. This creates a situation of rent and opportunities of profit for entrants. The notion of accommodation supply which defined the former hotel industry is replaced by the notion of solution, provided by for-profit KISS. Airbnb did not try to increase the hotel supply, it simply allowed anyone with spare houses, apartments or rooms to access the global market of tourism, to create their own business using the platform and solve the excess demand issue. It built its business model sharing the existing rent with the

\footnotetext{
${ }^{5}$ www.couchsurfing.com
} 
tourists and the renters, at the expense of the hotels.

The platform has been created in 2008 by Brain Chesky and Joe Gebbia in San Francisco, building on a small event. They were unemployed graduated designers who had moved to San Francisco and needed money. They thought they could make some cash by housing attendees at an industrial design conference in their apartment, because of the well know shortage of hotel going this important events in the city (Geron, 2013). The success of their initiative convinces them that a potential market existed; "We were just trying to solve our own problem. After we solved our own problem, we realized many other people want this.” (Chesky, quoted in Geron, 2013). They associated to Nathan Blecharczyk and created the Airbnb platform, a peer to peer online marketplace which received an immediate success. The platform connects users with “airbed equipped rooms to rent” (in fact rooms, apartments, houses, or even castles) with users looking to rent a space. It does not own any resource itself. The platform is free, as far as its viability depends of the increasing number of hosts and travelers registered, and the opportunity of matching. The network effects and the Web 2.0 principles govern the economic model, chiefly 'the service automatically gets better the more people use it'. Consequently, a valid email address and a valid telephone were initially the only requirements to build a unique user profile on the website. Hosts as well as Guests must register freely; a main feature of the platform economy is that a user can be either a Host or a Guest depending of its present problem to solve, can earn an additional income or find an accommodation.

The economic model of the peer to peer marketplaces is very different from the traditional accommodation model. The last one is governed by customers. Indeed hotels compete for customers trying to satisfy their needs through suitable services. In the platform economy the competition is first for the producers, the hosts, which enable value creation as far as platforms do not hold any resource. Without a critical mass of hosts, consumers cannot solve their problems of accommodation easily, and network effects cannot take off. The aggregation property of Web 2.0 turns individual users into a global marketplace. The efficient matching of the two sides of the market underlies value creation in the platform economy.

The platform can be considered as a radical innovation, not regarding technology but regarding the organization of the market and of the industry. It represents the figure of the knowledge based economy. Airbnb is born with not much financial capital or resources, but enough knowledge to assemble free pieces of software to build a platform matching a need to solve and set up the interactions allowing users to find solutions. Airbnb is a KISS and 
relinquishes ownership to the ecosystem. In this internet economy, the competitive advantage shift from resources to the ecosystem, the value is not in owning resources but in managing the marketplace, the market value does not come primarily from the consumers but from the producers which provide the resources. The result has been the surge of sources of supply never existed before and an unprecedented growth of the long tail, the real take-off of its exploration though the creation of new organization of the industry.

A lot of unknown initiatives have emerged with AirBnb in the accommodation segment, but the latter has succeeded to retrieve most of the network effects. Different elements are under its success. A first one is certainly the involvement in the project of Y Combinator, one of the most important venture capital of the Silicon Valley in 2008; in 2011 Airbnb had already raised \$120 million in venture funding from Y Combinator and many others venture funds. This allowed Airbnb to invest on two main key elements of the success of the platform strategy. The first has been a huge investment in Google Adwords, the online advertising service of Google that places contextual advertising with the search results Google displays for a particular search query. Airbnb gained a global visibility, as Google reaches out to the entire web. The second investment has been in its curation system to create an environment of trust between travelers and hosts, AirBnB invested in a strong curation mechanism, financing photographers to certify the rooms and houses host listing posted on the platform, but also Airbnb'visitors to help the host to enter in the activity and also control the quality of the resources, as 'the size of your reputation matters more than the size of your marketing budget' (Offutt, 2007). A robust review mechanism based on the usual systems of notation, comments and advices provided to the hosts and the guests complement the architecture of devices controlling the reputation, transparency effects. Airbnb had also the resources to finance a global strategy; they bought competing platforms in Europe, and financed also a curation strategy abroad, as a global firm. The nature of the problem addressed and the platform itself, i.e. the capability to capture value added in the design of solutions which meet the needs of tourists, have been fed by the knowledge of the Web 2.0 technology and economy, the "winner takes all" effect has been fed by the financial resources Airbnb benefited to create better mechanisms of trust and network effects. 
The business model of Airbnb can be summarized as shown in Figure 2.

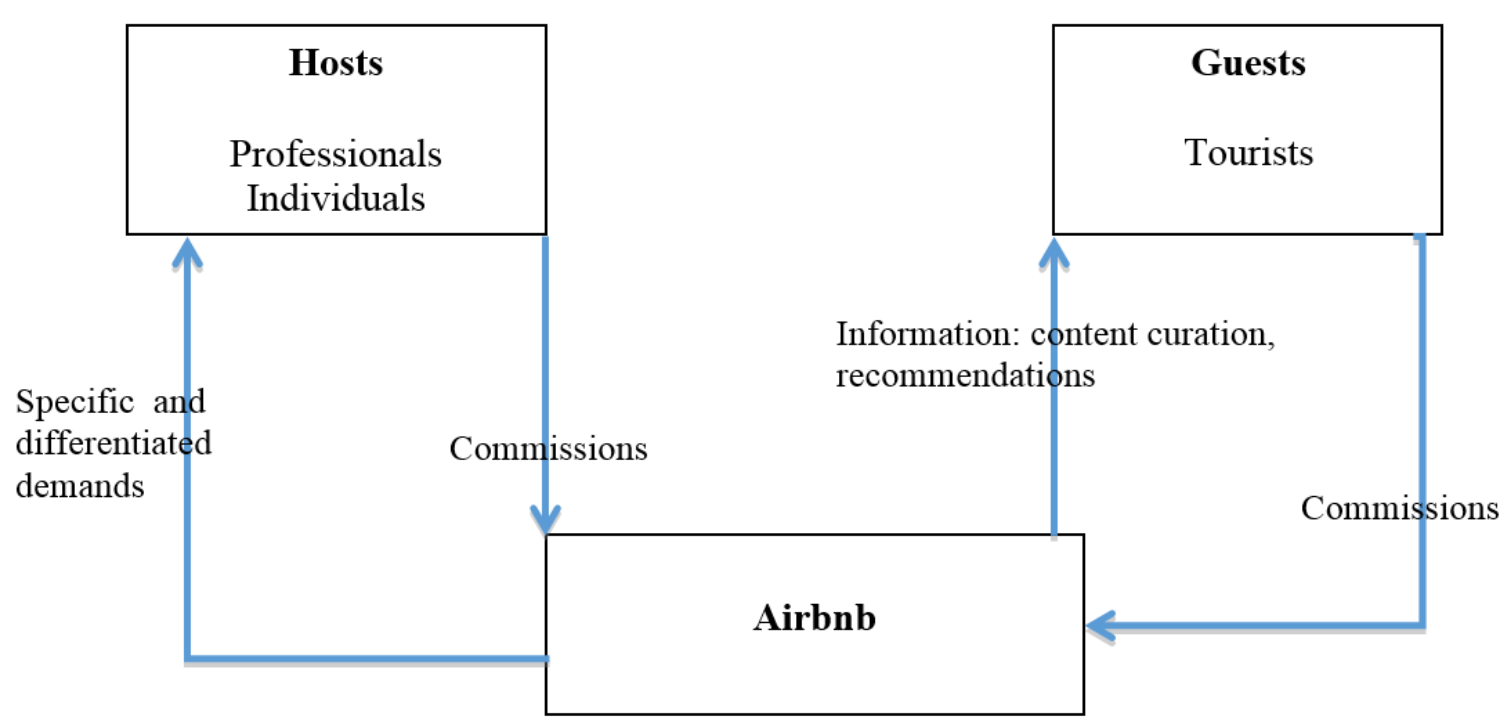

The inscription of the user on the platform is free. Then, as in every platform, one side of the market - the most important one regarding its viability or profitability - benefits from better conditions, which can be free use. In our case, platforms compete for producers, which provide the resources. Producers are thus only charged a commission of $3 \%$, when the guests are charged from 6 to $12 \%$ depending of the nature, quality or location of the room, the prices being set by the producers. The assessment of the activity of Airbnb is impressive; it provides access to a stock of 1000000 accommodations in 40000 cities, 192 countries, and involved 25000000 of users. The company has a valuation of approximately $\$ 10$ billion in 2014 that is more than most of the leaders of the traditional hotel industry.

Such a huge growth does not go without problems and accidents. Different cases are known in the sharing economy, from destruction of apartments to aggressions. The review mechanism set up by Airbnb has somewhat solved the last problem. The firm has also created an international department of aid for users available 24h/24, and an insurance system to protect the hosts until $€ 700000$. But the most important challenge refers to the last basic attribute of the sectoral system, i.e. institutions. Airbnb is a new entrant in the accommodation market on which it rapidly held a significant share, but on the basis of a totally new business model. It does not compete on the existing market, but has created a platform that allows users to run a bnb on the global accommodation demand, a new global market and new rules, without any comparison with the old ones. Problems of taxes, of VAT are raised, which underline unfair competition or 
even illegal practices. Indeed the rules of the global platform are uniformly adopted by users in cities and countries obeying very different laws ant tax systems. From Barcelona to San Francisco a lot of cases against the platform have been raised. Some institutional rearrangement will have to be implemented to redefine, standardize the rules and regulate the market.

The KISS get their strength out of the ecosystem they build. The users from the two sides of the markets are the main measure of their competitive position. With millions of users Airbnb has gained a leadership in the sharing economy, and has induced an extended specific ecosystem of associated platforms. Some renters can sublet some rooms the house they rent through Airbnb to earn some additional revenue for instance, which can be considered as forbidden. Huntbnb is a platform built for owners and dedicated to check if their properties have been listed on Airbnb without their permission. On the contrary other platforms have emerged to help the hosts to use Airbnb; for instance Bnbsitter or Bnbcare are two platforms dedicated to accommodate the guests, give them the keys, to prepare the apartments when the hosts cannot take care of these tasks. The logistic of short length renting is a growing ecosystem induced by the growth of the sharing economy as a marketplace.

The Long Tail 2.0 is fed by the continuous birth of KISS, Airbnb has obviously not a monopolistic position. A lot of for-profit and non-profit platforms exist, the first ones capturing the larger share of the activity. Our aim here is not to detail the different platforms competing on the peer to peer market place of accommodation, but to give an idea of the platform economy. Airbnb the leader in the global market with 1000000 accommodations, the other KISS are less than its half and often more attached to specific countries for guests. The Swiss House Trip created in 2010 is the second KISS with 250000 accommodation offers in Europe, followed by the Germans Wimdu created in 2011 and mainly active in Europe and Asia or 9flats, created in Hamburg in 2011 and offering 100000 apartments. These platforms have benefited from important venture capital funds. In France, Bedycasa created in 2009 offers only 20000 accommodations worldwide, Sejourning created in 2011 is focused on the French market, Chambrealouer created in 2009 focuses on single rooms and represents 16000 offers in 90 countries. Ficalaemcasa can be find in Brazil or Bedandfed in UK. Other platforms specialize in the market of holidays and longer stays, like Homeexchange (Trocmaison in France), Guest to Guest, HomeAway (Abritel in France), homeforhome among many others. After CouchSurfing which has created the concept, a lot of non-profit and free platforms are developing, help exchange, woofing, greeting, or more innovative initiatives, like Nightswapping, where the travel is 
based on the exchange of night between the members of the community associated to the platform, the night being the virtual money which rules the exchanges. Finally different niches are tackled, luxury homes (Le Collectionist) or apartments (Onefinestay), the market of cyclists (Warmshowers), and the camping on private gardens (Glamping) ${ }^{6}$.

Clearly some platforms concentrate most of huge share of the peer to peer marketplaces. The Long Tail 2.0 has grown to the point to develop its own economic model, independent of the Short Head, but inside the long tail itself power laws are clearly emerging, for the KISS, for the destinations; some platforms are running 80 or more of the activity, a lot of more confidential ones running a small share of the sharing economy. The same seems to be true in destination in Airbnb for instance. Recent analysis of the portfolio of Airbnb clearly shows that along with the users renting rooms for additional income exist more and more 'professionals' renting a lot of apartments, sometimes several dozens, a large share of the accommodation being finally offered by a small share of users. The "shape of Airbnb’business” (Slee, 2014) has been analyzed in depth in many cities following the first studies in New York (Slee, 2014), in San Francisco, Paris, London, Amsterdam, Geneva (Abbiateci, 2014). It appears that while a large number of hosts rent the homes they live in, the regular people Airbnb presents as users, hosts with multiple listings make up almost half of Airbnb’s business, over 40\% comes from hosts with multiple listings. The majority of Airbnb's revenue in New York comes from whole-home rentals (Slee, 2014), the same has been evidenced in all the cities the shape of Airbnb business has been analyzed. In fact some few multiple listings users concentrate most of the accommodation supply, back to power laws. Airbnb is also complementary to the existing tourism industry, for instance $70 \%$ of Airbnb properties in Paris being located outside the central hotel corridor, $73 \%$ of Airbnb properties in Amsterdam outside the eight central tourist districts (Slee, 2014). Airbnb is not only disrupting the tourism industry, it seems thus to disrupt even more the housing market in large cities. The evolution of the last attribute of the sectoral system, the institutions, regarding the so called sharing economy, will be pivotal to the future of accommodation market. Nevertheless regarding our main issue at stake, tails into the tails into the tails are again emerging into the long tail 2.0, the sharing economy aggregating microscopic offers on a global scale has finally resulted in the reemergence of power laws in the long tail itself.

\footnotetext{
${ }^{6}$ http://www.consoglobe.com/
} 


\section{Conclusion.}

The changes induced by the Internet in the travel and tourism activities have induced huge transformations the different dimensions are difficult to grasp. The boundaries of the industry have moved rapidly, far from extending and improving classic markets, the internet has produced in tourism an economic organization which appears completely new and which is still currently continuously renewed and even transgresses current regulation (Mc Affee \& Hendricks, 2003).

The concept of long tail used in this paper has allowed arranging and rationalizing the different steps of these transformations, as changes are embedded in the lengthening and thickening movements of the tail traced in the paper. Two main phases have been identified, the exploitation of the long tail, product oriented and driven by the traditional economy principle, the exploration of the long tail, service oriented and driven by the building of solution in dedicated ecosystems. The consumers have been more and more involved in the economic process, at first to produce the content of the web sites through review mechanisms, then to produce the resources exchanged or traded on the platforms, towards the emergence of Knowledge Intensive Service Suppliers. In this platform economy, users are alternatively consumers and producers, prosumers as often coined, depending of the purpose of the transaction at hand. In this last phase, huge global marketplaces are built into the long tail itself, because of the aggregation properties of Web 2.0. Regarding accommodation mainly grasped in this paper, two global models working on different economic processes and rules are facing and indirectly competing, a 'market economy' vs. a ‘platform economy', KISS being more and more important.

The SSIP of tourism is never gone through so strong disruptive transformations despite the deep evolutions it bears since the development of the Internet. Its frontier and knowledge bases have since continuously evolved, inducing changes in the organization of the industry. Nevertheless recently the core of the system, the institutions, has been hurt, as self-defined new rules enacted by the entrants have resulted in the emergence of a rival system facing the traditional one. The organization of the industry and the market is shaped by institutions; arrangements will have to be made in the relations between the national institutions and the sectoral system to harmonize the rules.

The sharing economy, the peer to peer market places, which were hard to imagine some few years ago have captured large areas to the society through the emergence of KISS in the Long Tail 2.0. Tourists and more largely citizens are looking for knowledge intensive platforms in order to find adaptive solutions to their changing uses. With mobile technologies, the services 
in this way produced by the KISS help tourists to design such a solution for each specific need at any place and time. In this "shift from the generic to the specific" (Anderson, 2008: 181), the notion of product which defined the former tourism economy is replaced by the notion of solution. Solutions are designed in order to solve various problems and specific needs. The most robust feature in this changing and deeply evolving society appears to be power laws; as it has been shown at the end of the peer to peer marketplaces revolution, power laws emerge as the shape of the business model.

\section{References}

Abbiateci J., 2014, Comment nous avons enquêté avec les données d'Airbnb, Data Le Temps, November 9, http://dataletemps.github.io/2014/11/09/airbnb.html

Aldebert B., Dang R.J., Longhi. C., 2011, Innovation in the Tourism Industry: The Case of Tourism@, Tourism Management, 32(5), 1204-1213.

Anderson C., 2004, The Long Tail. WIRED magazine. Issue 12.10, October, 1-5

Anderson C., 2008, The Long Tail. Why the Future of Business is selling Less of More. Hachette Books.

Baggio R., 2008, Symptoms of Complexity in a Tourism System. Tourism Analysis, vol. 13, 1-20

Botsman R., Roo R., 2011, What's Mine is Yours: How Collaborative Consumption is Changing the Way We Live, Collins, London

Brynjolfsson E., Hu Y.J, Smith M.D, 2010, Long Tails vs. Superstars: The Effect of Information Technology on Product Variety and Sales Concentration Patterns (Research Commentary). Information Systems Research, 21 (4), 736-747. http://dx.doi.org/10.1287/isre.1100.0325

Brynjolfsson E., Hu Y.J., Simester D., 2011, Goodbye Pareto Principle, Hello Long Tail: The Effect of Search Costs on the Concentration of Product Sales, Journal of Management Science, Vol. 57, Issue 8, August, 1373-1386.

Buhalis D., Law R., 2008, Progress in Information Technology and Tourism Management: 20 Years on and 10 Years after the Internet-The State of eTourism Research, Tourism Management, 29(4), 609623.

Buhalis D., Licata M.C., 2002, The future of eTourism intermediaries, Tourism Management, 23, 207220.

Buhalis D., Zoge M., 2007, The Strategic Impact of the Internet on the Tourism Industry. In M. Sigala, L. Mich, J. Murphy (eds), Information and Communication Technologies in Tourism 2007, 481-492. Wien: Springer-Verlag,

Caccomo J.L., Solonandrasana B., 2001 L'innovation dans le tourisme. Enjeux et stratégies, Paris, Coll. Tourismes et Sociétés, L'Harmattan.

Choudary S. P., 2014, From social media to the sharing economy: the three drivers of business disruption, June 5, Platform Thinking, http://platformed.info/

Day J., Ward L., Choi S-h., Zhao C., 2011, Catching the long tail: competitive advantage through distribution strategy, Journal of Hospitality and Tourism Technology, vol. 2, 3, 204-215

Evans D.S., 2011a, Platform Economics. Essays on Multi-Sided Businesses. Competition Policy 
International.

Evans D.S, 2011b, The Internet of Things How the Next Evolution of the Internet Is Changing Everything, CISCO White Paper, April, San Jose, 2011.

Geron T., 2013, Airbnb and The Unstoppable Rise Of The Share Economy, February 11, 2013 issue of Forbes, http://www.forbes.com/

Hall C. M., Williams A.M., 2008, Tourism and Innovation, London: Routledge.

Hedrick-Wong Y., Choong D., 2014, MasterCard Global Destination Cities Index, MasterCard Worldwide Insights

Hess C., Ostrom E., 2007, Introduction: An Overview of the Knowledge Commons, in Hess C. and Ostrom E. eds, Understanding Knowledge as a Commons. From Theory to Practice, The MIT Press

Hjalager A.M., 2002, Repairing Innovation Defectiveness in Tourism. Tourism Management, 23, 465474.

Hjalager A.M., 2010, A Review of Innovation Research in Tourism. Tourism Management, 31(1), 1-12.

Kim W.G., Lee C., Hiemstra, S.J., 2004, Effects of an online community on customer loyalty and travel product purchases, Tourism Management, Vol.25 (3), June, 343-355.

Kozinets R.V., 1999, E-tribes and marketing : virtual communities of consumption and their strategic marketing implications, European Management Journal, 17 (3), 252-264.

Lew A.A., 2005, Long Tail Tourism, The $2^{\text {nd }}$ Tourism Outlook Conference - Tourism Edge and Beyond, 4-6 December 2005, Shah Alam, Selangor, Malaysia

Lew A.A., 2008, Long tail tourism: New geographies for markeing niche tourism products, Journal of Travel \& Tourism Marketing, Vol. 25(3-4), 409-418.

Leiper N., 1979, The Framework of Tourism : Towards a definition of tourism, tourist, and the tourist industry, Annals of Tourism Research, Volume 6, Issue 4, 390-407

Liburd J. J., 2012, Tourism Research 2.0, Annals of Tourism Research, 39(2), 883-907.

Longhi C., 2003, Quelle offre ? Des acteurs - opérateurs composites, in J. Spindler ed., Le tourisme au XXI siècle, L’Harmattan, Paris

Longhi C., 2009, Internet and Organisation of the Industry in Tourism: A Focus on the Distribution of Travel and Tourism Services, Int. J. Leisure and Tourism Marketing, 1(2), 131-151.

Malerba F., 2001, Sectoral systems of innovation and production: concepts, analytical framework and empirical evidence, ECIS Conference "The Future of Innovation Studies", Eindhoven September 2023

Malerba F., 2002, Sectoral systems of innovation and production, Research Policy 31 247-264

Malerba F., 2004, Sectoral Systems of Innovation: Basic Concepts. In F. Malerba (ed.), Sectoral Systems of Innovation, Concepts, Issues and Analyses of Six Major Sectors in Europe. Cambridge, MA: Cambridge University Press, 2004. 9-35

March J., 1991, Exploration and exploitation in organizational learning, Organization Science, vol.2, 1, 71-87

Mc Afee R.P., Hendricks K., 2003, Evolution of the market for air-travel information, mimeo, University of Texas at Austin, March

Miles I., 2001, Services Innovation: A Reconfiguration of Innovation Studies. PREST Discussion Papers 01-05, April; University of Manchester, 2001. http://www.mbs.ac.uk/research/innovation /publications-archive/documents/PRESTDP01-05.pdf

Miozzo M., Grimshaw D., 2006, Knowledge intensive business services: understanding organisational 
forms and the role of country institutions. In M. Miozzo and D. Grimshaw (Eds), Knowledge Intensive Business Services: Organisational Forms and National Institutions. Cheltenham: Edward Elgar

Miranda S., 2012, Les nouveaux paradigmes du tourisme mobiquitaire.” MBDS, University Nice Sophia Antipolis, mimeo.

Murmann J.P, 2003, Knowledge and Competitive Advantage. The Coevolution of Firms, Technology, and National Institutions. Cambridge University Press, Cambridge.

Offutt B., 2007, PhoCus Wright's five predictions about the future of the Long Tail in travel. Presented at the PhoCus Wright Conference, Orlando, Florida, November

O’Reilly T., 2006, Web 2.0 Compact Definition: Trying Again, December 10, Radar, http://radar.oreilly.com/

O’Reilly T., Battelle J., 2009, Web Squared: Web 2.0 Five Years On, Special Report. San Francisco: O’Reilly Media Techweb, 2009.

Ostrom E., Hess C., 2007, A Framework for Analyzing the Knowledge Commons. In Hess C. and Ostrom E. eds, Understanding Knowledge as a Commons. From Theory to Practice, The MIT Press

Poon A., 1989, Competitive strategies for new tourism, in Cooper, C., (ed.), Progress in Tourism Recreation and Hospitality Management, Vol.1, Belhaven Press, London, 91-102.

Rosen S., 1981, The Economics of Superstars. The American Economic Review, vol.71, 5, 845-858.

Slee T., 2014, The shape of Airbnb’s business, Whimsley May 26, http://tomslee.net/

Tether B.S., Metcalfe J.S., 2004, Services and Systems of Innovation. In F. Malerba (ed.), Sectoral Systems of Innovation, Concepts, Issues and Analyses of Six Major Sectors in Europe. Cambridge, MA:Cambridge University Press, 2004.

The Economist, 2005, Profiting from obscurity, May 5, www.economist.com/node/3936129

Thevenot G., 2007, Blogging as a Social Media, Tourism and Hospitality Research, 7, 287-289.

Tremblay, P. 1998 The economic organization of tourism, Annals of Tourism Research, Volume 25, Issue 4, October, 837-859

Wade, Ph., 2001, Impact des nouvelles technologies sur les systèmes d'information et de réservation touristique, Rapport au Conseil National du Tourisme, http://www.tourisme.gouv.fr

Wade Ph., Raffour G., 2000, Tourisme et technologies de l'information et de la communication : le futur est déjà là, Rapport au Conseil National du Tourisme, http://www.tourisme.gouv.fr

Wang Y., Yu Q., Fesenmaier D.R., 2002, Defining the virtual tourist community: implications for tourism marketing, Tourism Management 23, 407-417

Wang R., 2013, Monday's musings: four elements for a \#SharingEconomy biz model in \#MatrixCommerce, May 26, Software Insider.

Werthner H., Klein S., 2005, ICT-enabled Innovation in Travel and Tourism. In B. Walder, K. Weiermair, A. Pérez (eds), Innovation and Product Development in Tourism, 71-84. Berlin: Erich Schmidt Verlag, 2005. 


\section{DOCUMENTS DE TRAVAIL GREDEG PARUS EN 2015 GREDEG Working Papers Released in 2015}

2015-01 Laetitia Chaix \& Dominique Torre

The Dual Role of Mobile Payment in Developing Countries

2015-02 Michaël Assous, Olivier Bruno \& Muriel Dal-Pont Legrand

The Law of Diminishing Elasticity of Demand in Harrod's Trade Cycle (1936)

2015-03 Mohamed Arouri, Adel Ben Youssef \& Cuong Nguyen

Natural Disasters, Household Welfare and Resilience: Evidence from Rural Vietnam

2015-04 Sarah Guillou \& Lionel Nesta

Markup Heterogeneity, Export Status and the Establishment of the Euro

2015-05 Stefano Bianchini, Jackie Krafft, Francesco Quatraro \& Jacques Ravix Corporate Governance, Innovation and Firm Age: Insights and New Evidence

2015-06 Thomas Boyer-Kassem, Sébastien Duchêne \& Eric Guerci Testing Quantum-like Models of Judgment for Question Order Effects

2015-07 Christian Longhi \& Sylvie RochHia

Long Tails in the Tourism Industry: Towards Knowledge Intensive Service Suppliers 